\title{
Une levure sans télomérase
}

Myriam S. Singer et Daniel E. Gottschling (Chicago, IL, USA)[1] viennent de cloner la matrice ARN de la télomérase de levure (Saccharomyces cerevisiae). Il s'agit là d'un progrès extrêmement significatif car il permet de confirmer le rôle de cette enzyme clé et laisse présager des développements d'un intérêt considérable sur le plan des connaissances et, peutêtre, de la thérapeutique. La télomérase est une ribonucléoprotéine constituée d'une ou de plusieurs sous-unités protéiques et d'une molécule d'ARN comportant une séquence complémentaire des répétitions caractéristiques de l'extrémité des télomères, c'est-à-dire 5'-CAACCC-3' dans le cas de Tetrahymena. C'est dans ce dernier organisme qu'a été réalisé l'essentiel des travaux princeps sur la télomérase car celle-ci y est particulièrement abondante, du fait de la présence d'un très grand nombre de molécules d'ADN nucléaire, c'est-àdire d'extrémités télomériques à protéger à chaque division. Rappelons que, lors de la réplication, la synthèse du brin complémentaire de l'une des chaînes d'ADN se fait à partir de petites amorces ARN (les fragments de Okasaki) $\left(m / s n^{\circ} 5\right.$, vol. 6, p. 488). Ce mécanisme empêche naturellement le recopiage complet à partir des extrémités qui sont donc inéluctablement rabotées à chaque cycle cellulaire. Ce phénomène n'est évité que grâce à une synthèse réparatrice des télomères, ce qui est le rôle de la télomérase se servant de son ARN comme matrice afin de réallonger l'extrémité rabotée $\left(m / s n^{\circ} 7\right.$, vol. $8, p$. 738). L'activité télomérase semble pratiquement absente des cellules normales, ce qui aboutit à une réduction mères qui pourrait constituer une véritable horloge biologique impliquée dans le vieillissement cellulaire. En revanche, l'activité télomérase serait stimulée lors de la transformation cancéreuse, permettant alors à ces cellules transformées de se diviser indéfiniment sans risquer cette réduction progressive de leurs extrémités télomériques $\left(\mathrm{m} / \mathrm{s} \quad n^{\circ} 8-9\right.$, vol. 10 , p. 912) . Singer et Gottschling ont débuté leur étude en mettant au point chez $S$. cerevisiae un crible pour des molécules intervenant dans la répression transcriptionnelle de gènes en situation télomérique. En effet, la structure de la chromatine des télomères (hétérochromatine) réprime fortement la transcription des gènes. Deux marqueurs de sélection, l'un conférant l'auxotrophie pour l'uracile et l'autre permettant la biosynthèse de l'adénine, ont été placés en situation télomérique où ils sont inactifs. Les levures ainsi obtenues ont été transfectées avec des clones d'ADNc de levure dans des vecteurs d'expression et les colonies ayant activé leurs deux gènes marqueurs ont été sélectionnées. L'idée de ce crible est que la surproduction de tout ou partie d'un des constituants du système de répression télomérique des gènes pourrait interférer avec cette répression et aboutir à une désinhibition. Dix clones différents ont été obtenus dont l'un est transcrit en un ARN TLC1 de 330 paires de bases pb. L'ARN TLC1 comporte la séquence UGUGGGUGUG qui pouvait être prédite d'après la séquence des répétitions télomériques de levure. La surexpression de TLC1 aboutit à une réduction de la taille des télomères, de même que l'inactivation du gène TLC1 par recombinaison homo- logue: les levures tlcl subissent une réduction de leurs télomères de $3 \mathrm{pb}$ par cycle cellulaire et leur croissance diminue après 60 à 75 générations. La mutation dans TLC1 de la séquence complémentaire des éléments répétés des télomères aboutit à l'incorporation de cette mutation dans des télomères néof ormés.

Le mécanisme par lequel la surproduction ou l'absence de TLC1 aboutit à une désinhibition de gènes en situation télomérique ne peut que faire l'objet de spéculations. Une première hypothèse est que le complexe stabilisant la région télomérique dans une configuration chromatinienne non permissive ne se forme plus lorsque les télomères se raccourcisent. Alternativement, il se pourrait que la télomérase fît elle-même partie du complexe d'inactivation.

La puissance des méthodes génétiques chez la levure va maintenant sans nul doute permettre de caractériser d'autres constituants de la télomérase, notamment la ou les sousunité(s) protéique(s), ainsi que d'autres protéines impliquées dans l'édification de la structure chromatinienne des télomères. Le rôle de la télomérase dans le vieillissement cellulaire et dans la transition vers la transformation cancéreuse en font naturellement une cible extrêmement attirante pour le développement de produits spécifiques en modulant l'activité. C'est cette recherche qui va sans nul doute être stimulée grâce aux travaux de l'équipe de Chicago.

A.K.

1. Singer MS, Gottschling DE. TLC1: template RNA component of Saccharomyces cerevisiae telomerase. Science 1994 ; 266 : 404-9. 